\title{
以三苯三戊并烯或窗狮满为核心的非平面纳米石墨烯
}

\author{
吴振辉 ${ }^{a}$ 王伟丞 ${ }^{a}$ 叶皓宏 ${ }^{a}$ 刘永华 ${ }^{a}$ 孙晓庆 ${ }^{a}$ 谢浩荣 $^{a}$ \\ 何丽思 ${ }^{a}$ 张以诺 ${ }^{a}$ Dietmar $\mathrm{Kuck}^{*}, b$ 周克勋*, \\ ( ${ }^{a}$ 香港中文大学化学系 中国香港) \\ ( ${ }^{b}$ 比勒费尔德大学化学系及分子材料中心 $\left(\mathrm{CM}_{2}\right)$ 德国比勒费尔德 33615$)$
}

\begin{abstract}
摘要 总结了我们近年合成的以三苯三戊并烯或窗䒢满为骨架的非平面纳米石墨烯之研究成果. 巫师帽形或鞍形的纳 米石墨烯可由非经典的 Scholl 环庚三烯环化或 19 元环大环化反应制备. 这些反应成功的关键是在这些分子的湾区区域 引入恰当的富电子芳香官能团, 通过 X 射线晶体学, 一些纳米石墨烯的三维结构可以得到确定. 此外, 这些富含碳的 $\pi$ 共轭分子还显示出有趣的光物理、自缔合和主-客体络合的特性.
\end{abstract}

关键词 非平面芳香族; 纳米石墨烯; 三苯三戊并烯; 窗䒢满

\section{Nonplanar Nanographenes Based on Tribenzotriquinacene or Fenestrindane Core}

\author{
$\mathrm{Ng}$, Chun-Fai ${ }^{a}$ \\ Wong, Wai-Shing ${ }^{a}$ \\ Ip, Ho-Wang ${ }^{a}$ \\ Lau, Wing-Wa ${ }^{a}$ \\ Sun, Xiao-Qing ${ }^{a}$ \\ Tse, Ho-Wing ${ }^{a}$ \\ He, Lisi ${ }^{a}$ \\ Cheung, Enoch ${ }^{a}$ \\ Kuck, Dietmar ${ }^{*, b}$ \\ Chow, Hak-Fun ${ }^{*, a}$ \\ $\left({ }^{a}\right.$ Department of Chemistry, The Chinese University of Hong Kong, Hong Kong, China) \\ ( ${ }^{b}$ Department of Chemistry and Center for Molecular Materials $\left(\mathrm{CM}_{2}\right)$, Bielefeld University, 33615 Bielefeld, Germany)
}

\begin{abstract}
Our recent research efforts on the synthesis of nonplanar nanographenes bearing tribenzotriquinacene or fenestrindane skeleton are summarized. Wizard hat-shaped or saddle-shaped nanographenes could be prepared using a non-classical Scholl-type cycloheptatriene formation or 19-membered ring macrocyclization. The key to the success of these transformation relies on the proper installation of the electron rich aryl functional groups in the bay areas of these molecular motifs. The three-dimensional structures of some of the nanographenes were determined by X-ray crystallography. Furthermore, these carbon-rich $\pi$-conjugated molecules are also showed to have interesting photophysical, self-assoication and host-guest complexation properties.

Keywords nonplanar aromatics; nanographenes; tribenzotriquinacene; fenestrindane
\end{abstract}

Nonplanar nanographenes are a special class of carbon-rich materials with interesting structural, physical and chemical properties. ${ }^{[1-7]}$ These curved molecules are usually synthesized by the so-called 'bottom-up' strategy ${ }^{[1]}$ as it affords products with controlled topology and better structural homogeneity. Three different methods have been designed to induce curvature into the nanographene structures. The first approach involves the introduction of nonhexagonal rings into a polyaromatic molecule. ${ }^{[4-6]}$ The second method relies on the creation of contortion via steric crowding of substituents in a congested polyaromatic skeleton. ${ }^{[8-10]}$ The third approach, initially proposed by one of us, ${ }^{[11-12]}$ entails the insertion of a few $\mathrm{sp}^{3}$-hybridized carbon atoms, which can then create a curvature surface and structural defective points into the nanographene unit. This account will summarize our research endeavors in the realization of incorporating either a tribenzotriquinacene (TBTQ) or a fenestrindane unit into polyaromatic hydrocarbon molecules to construct bowl-shaped and saddleshaped nanographenes, respectively.

\footnotetext{
* Corresponding author. E-mail: hfchow@cuhk.edu.hk

Received May 29, 2020; revised July 20, 2020; published online July 30, 2020.

Dedicated to Professor Henry N. C. Wong on the occasion of his 70th birthday.

Project supported by the Research Grants Council of Hong Kong Special Administration Region (No. 14303816)

香港特别行政区研资局(No. 14303816)资助项目.
} 


\section{Tribenzotriquinacene-derived nanogra- phenes}

The TBTQ skeleton, a member of the molecular family of centropolyindanes, ${ }^{[13]}$ consisting of three indane units that share the central carbon atom, was first synthesized by Kuck et al. (Figure 1). ${ }^{[14-15]}$ This molecular framework possesses a very interesting topology in which the three indane wings are aligned in an orthogonal relationship that extends towards the $x, y$ and $z$ directions in the three dimensional space. ${ }^{[13,16-18]}$ As a result, the molecule has been utilized to serve as the corners of a molecular square ${ }^{[19]}$ and of covalently and non-covalently bonded molecular cubes. ${ }^{[20-23]}$ The idea of bay bridging the three aromatic rings inside the TBTQ unit via unsaturated functionalities had also become a hot pursuit, because such a strategy would lead to a nonplanar, bowl-shaped nanographene system, which could pave way towards the synthesis of novel host systems for encapsulation of guest molecules (Scheme 1). ${ }^{[11,13,17,24]}$
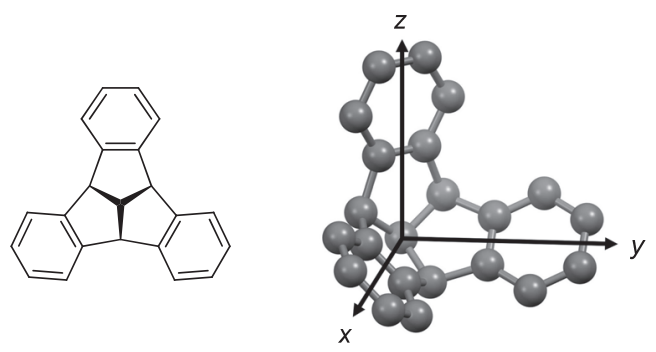

Figure 1 Structure and three-dimensional geometry of TBTQ

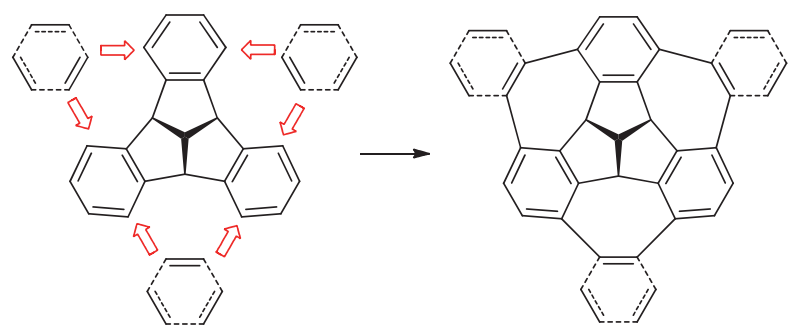

Scheme 1 Bay bridging of a TBTQ unit with three vinylene or ortho-phenylene units

However, introduction of functionalities into the bay areas of the TBTQ skeleton poses a synthetic challenge as such positions are sterically hindered. Indeed, direct electrophilic aromatic substitution reactions on the TBTQ framework resulted predominately in the formation of periphery-functionalized derivatives. ${ }^{[11,13,25-26]}$ Rather interestingly, the first successful TBTQ bay bridging with a hexa-peri-hexabenzocoronene (HBC) unit actually involved the periphery-functionalized TBTQ derivative $\mathbf{1}$ (Scheme 2). ${ }^{[27]}$ The reaction was believed to proceed with the initial formation of six hexagonal rings via the classical Scholl reaction, ${ }^{[28-30]}$ followed by a non-classical cycloheptatriene ring formation under the same reaction conditions to give product 2 . ${ }^{1} \mathrm{H}$ NMR signal broadening of compound $\mathbf{2}$ was noted, indicating significant intermolec- ular aggregation at room temperature.
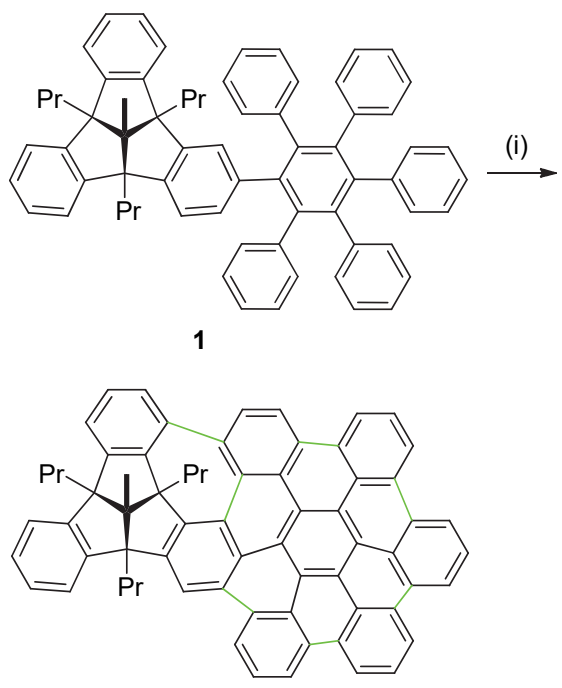

2

Reagents and conditions: (i) $\mathrm{AlCl}_{3}, \mathrm{Cu}(\mathrm{OTf})_{2}, \mathrm{CS}_{2}, 45{ }^{\circ} \mathrm{C}, 59 \%$ yield

Scheme 2 First successful bay bridging of a TBTQ derivative 1 using a $\mathrm{HBC}$ unit

Prompted by this initial success, the threefold cycloheptatriene formation on all three bay areas of the TBTQ derivative 3 was pursued (Figure 2). ${ }^{[31]}$ Unfortunately, such attempts were not successful. The presumed poor solubility of the product and unfavorable electronic properties of the reactant may be the reasons for the failure. It has been well documented that the Scholl reaction requires the presence of electron-donating substituents at the correct positions in order to proceed smoothly. ${ }^{[32-33]}$

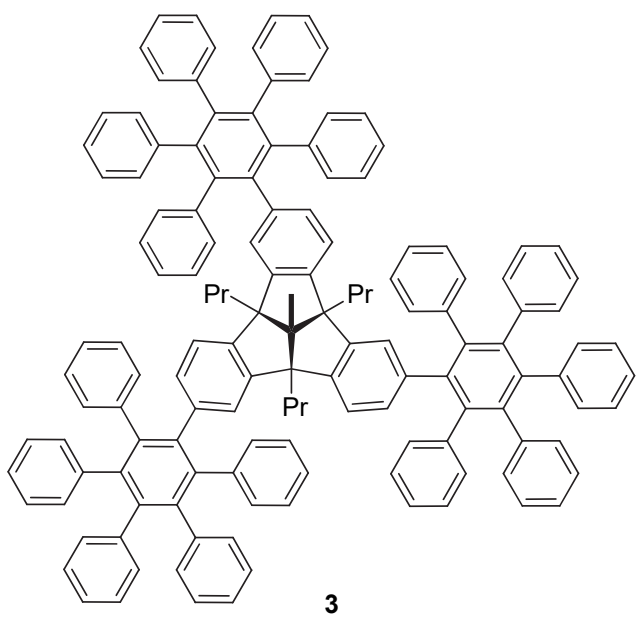

Figure 2 Unsuccessful threefold cycloheptatriene formation involving compound $\mathbf{3}$

An alternative strategy was then employed to realize the threefold bay-bridging process (Scheme 3$).{ }^{[34]}$ In this case, the tris-(bay area)-functionalized TBTQ derivative $\mathbf{6}$ was prepared. As mentioned earlier, direct functionalization of the parent TBTQ molecule gave mainly peripherysubstituted products, therefore compound $\mathbf{6}$ was synthe- 
sized starting from the appropriate functionalized precursors $\mathbf{4}$ and $\mathbf{5}$ before establishing the TBTQ skeleton. Due to steric repulsion effects, the yield of compound $\mathbf{6}$ was very low. Nonetheless, it could be prepared in a few steps in relatively large quantities. Compound $\mathbf{6}$ was then converted into a series of triaryl-functionalized TBTQ derivatives 8 via tris(triflate) 7 .

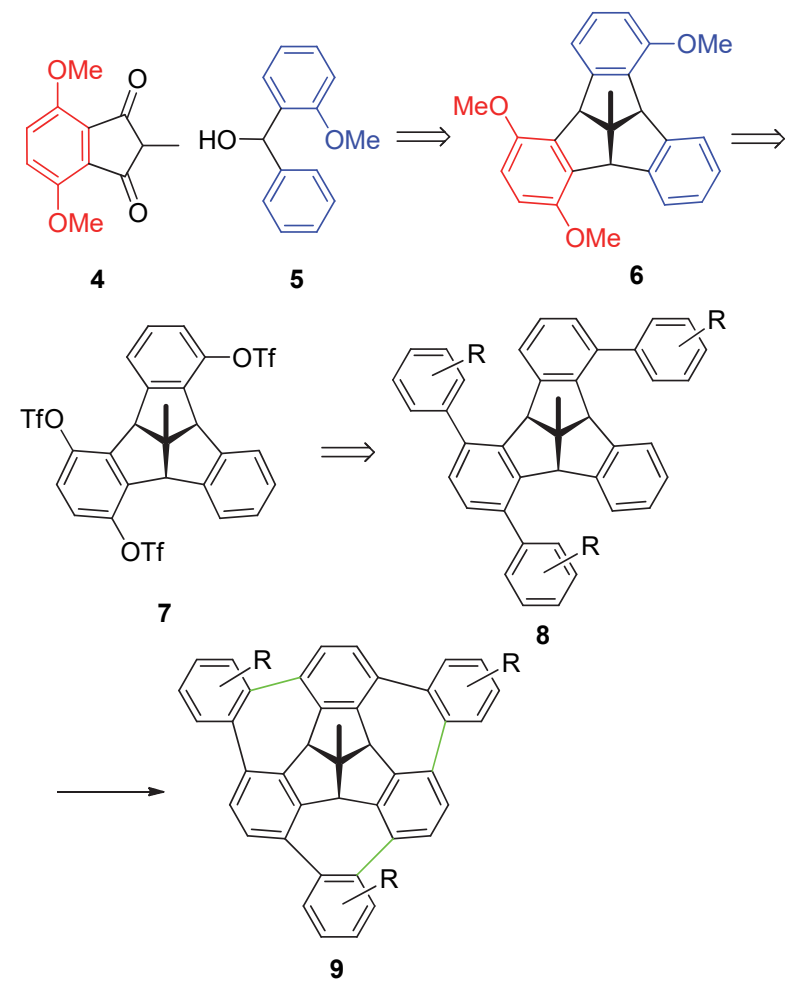

Reagents and conditions: (i) DDQ, TfOH, $\mathrm{CH}_{2} \mathrm{Cl}_{2}, 0{ }^{\circ} \mathrm{C}$

Scheme 3 Threefold bay bridging of the tris-(bay-functionalized) TBTQ compound 7 prepared from precursors 4 and 5

Threefold cycloheptatriene formation was then carried out using the various substituted TBTQ derivatives $\mathbf{8}$ in the presence of 2,3-dichloro-5,6-dicyano-1,4-benzoquinone (DDQ) and triflic acid. Among all the TBTQ derivatives, only those bearing three 3,4-dimethoxyphenyl or 2,3,4trimethoxyphenyl substituents reacted as desired to give the threefold cyclization products $\mathbf{1 0}$ and $\mathbf{1 1}$, respectively (Figure 3). ${ }^{[34-35]} \mathrm{V}$-Shaped single-cyclization products, such as $12 \sim 16$, were also isolated, but they could not be further converted into the corresponding threefold cyclization products. It was also found that bridgehead hydroxylation (e.g. 12 and 13) and/or rearrangement products were formed during the reactions. On the other hand, no doubly cyclized product was isolated or detected in these experiments, indicating that, once formed, such a compound rapidly underwent the third cyclization. Overall, it was concluded that electron-donating substituents are required to promote the cycloheptatriene formation, but that they also have to be substituted at the appropriate positions.

The crystal structure of the threefold cyclized product $\mathbf{1 0}$
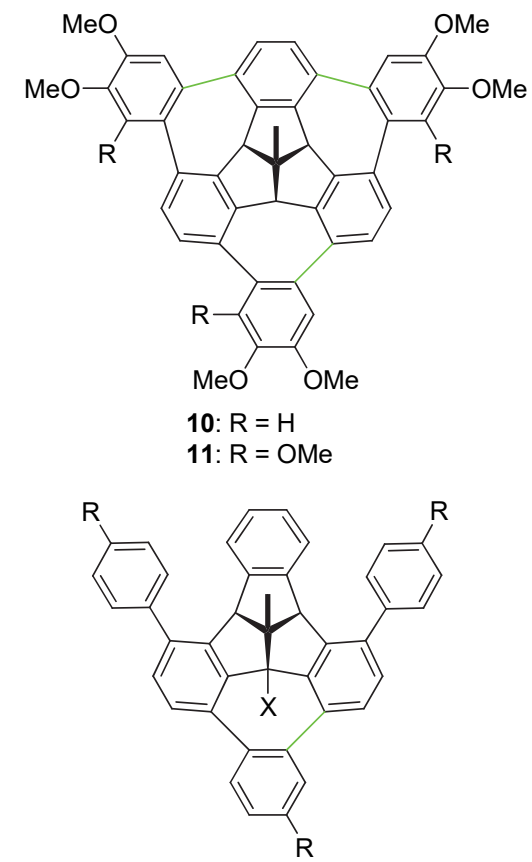

12: $\mathrm{R}=\mathrm{H}, \mathrm{X}=\mathrm{OH}$

13: $\mathrm{R}=t-\mathrm{Bu}, \mathrm{X}=\mathrm{OH}$

14: $\mathrm{R}=\mathrm{OMe}, \mathrm{X}=\mathrm{H}$

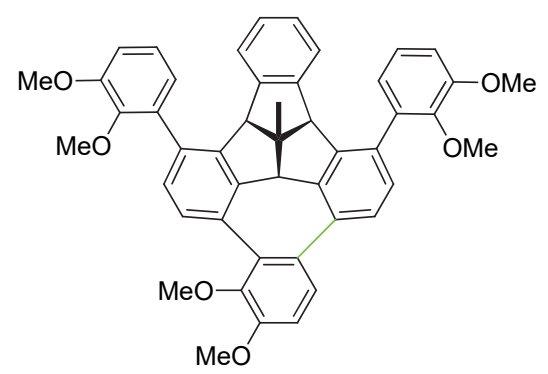

15

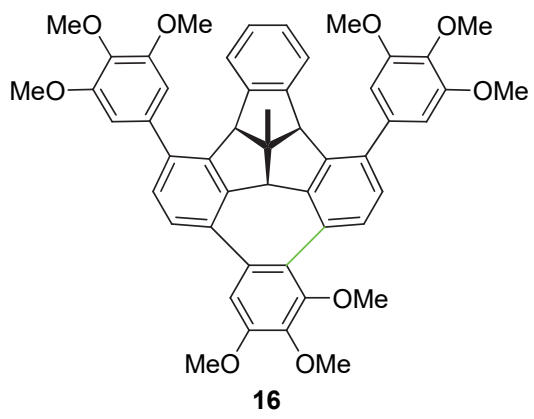

Figure 3 Threefold 10, 11 and single-cycloheptatriene formation products $12 \sim 16$ (newly formed bonds highlighted in green).

was determined (Figure 4). ${ }^{[36]}$ The compound was found to adopt a wizard hat-shaped structure. The ortho- and paraphenylene rings are oriented in a more coplanar manner as compared to those in the calculated geometry of $o, p, o, p, o, p$-hexaphenylene, ${ }^{[37]}$ indicating that the extent of $\pi$-conjugation was improved by fixing the aryl rings around the triquinacene core.

The availability of the six methoxy groups in compound 


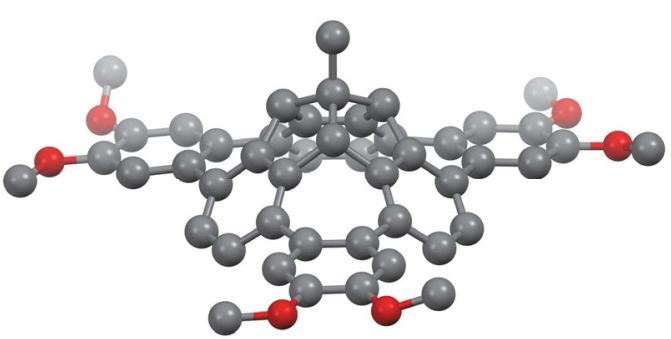

Figure 4 Crystal structure of compound $\mathbf{1 0}$

10 could allow further $\pi$-expansion to prepare larger-size nanographenes (Scheme 4). For example, the hexakis(triflate) $\mathbf{1 7}$ should be obtainable from compound $\mathbf{1 0}$ via simple functional group transformation. Subsequent
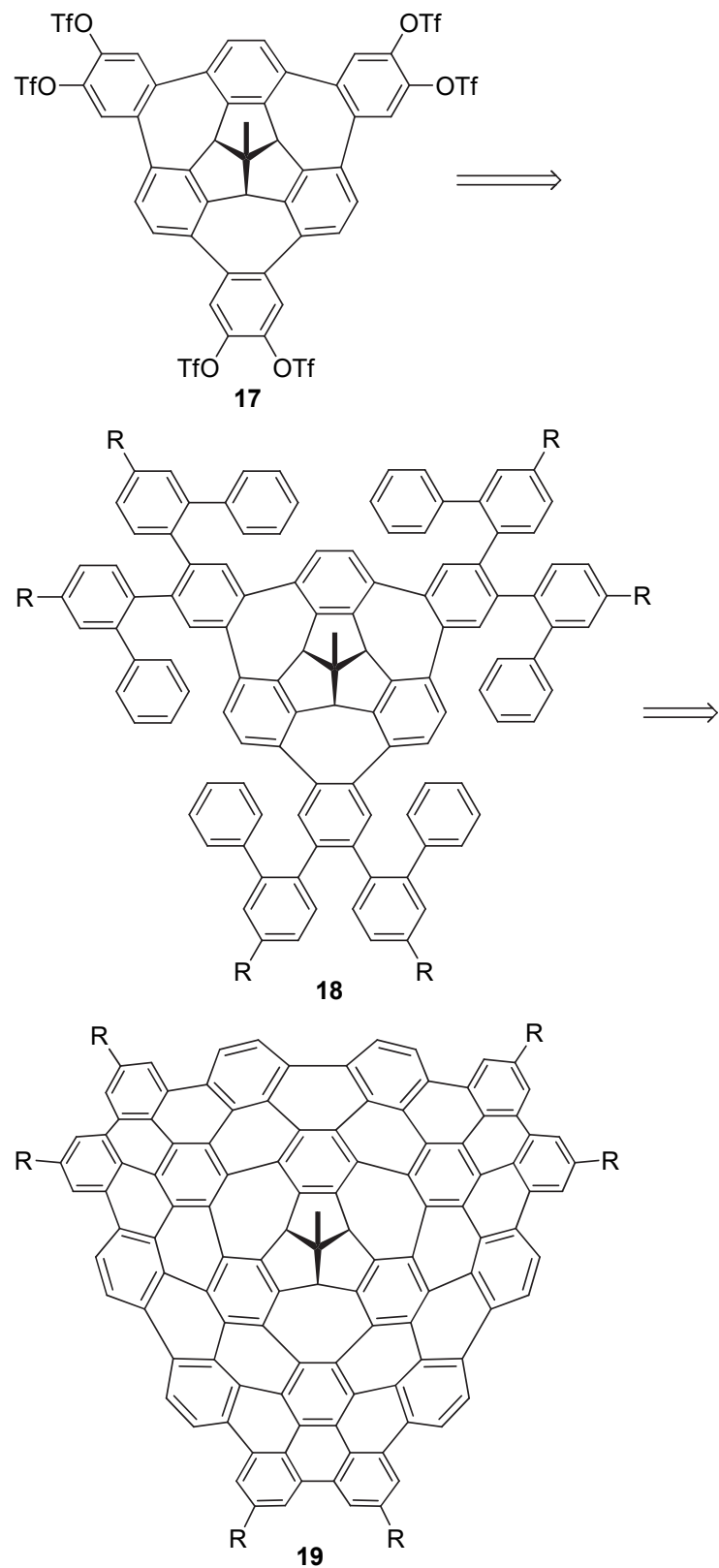

Scheme 4 Potential further $\pi$-expansion on compound 17 sixfold Suzuki-Miyaura coupling could produce compound 18, which in turn could lead to the larger nonplanar nanographene 19 via Scholl-type cyclization. It was noted that long-chain alkyl groups (R) are required to ensure good solubility of the resulting product.

Recent interest in the structure and properties of multiporous nanographenes ${ }^{[38-41]}$ also prompted us to make use of the TBTQ skeleton to prepare trefoil-shaped porous nanographenes via a threefold Scholl-type macrocyclization (Scheme 5). ${ }^{[42]}$ Starting from the "peripheral" TBTQ hexakis(triflate) 20, Suzuki-Miyaura coupling with 3-methoxyphenylboronic acid afforded the sixfold coupling product 21 in $95 \%$ yield. Subsequent threefold Scholl cyclization using $\mathrm{FeCl}_{3}$ then produced compound 22 in $98 \%$ yield. Sixfold ether cleavage and triflation followed by a second sixfold Suzuki-Miyaura coupling with 2-(n-dodecyloxy)phenylboronic acid gave product $\mathbf{2 3}$ in an $60 \%$ overall yield. Finally, threefold 19-membered ring macrocyclization proceeded smoothly to afford the porous nanographene 24 in $86 \%$ yield. The very high yielding of the final macrocyclization suggested that each of the three pairs of to-be-connected aryl rings was pre-organized in close proximity at the bowl-shaped TBTQ skeleton. X-Ray crystallographic analysis of compound $\mathbf{2 5}$, an aryl analog of $\mathbf{2 4}$, confirmed that the molecule possesses a distorted wizard hat-shaped geometry consisting of three macrocycles with a pore size of $0.29 \sim 0.30 \mathrm{~nm}$ (Figure 5). ${ }^{[43]}$ Compound 25 was also found to be a host of chloride ion with a binding constant of $88 \mathrm{~L} \cdot \mathrm{mol}^{-1}$ in $\mathrm{CH}_{2} \mathrm{Cl}_{2}$ and a 1 : 1 binding stoichiometry. DFT calculations suggested that the six inner $\mathrm{C}\left(\mathrm{sp}^{2}\right)-\mathrm{H}$ bonds were responsible for interacting with the chloride ion. Incidentally, a similar anion-binding property of such carbon-based macrocycles was also reported by Kim and Stępien, ${ }^{[44]}$ suggesting that this type of porous nanographenes represent genuine anion-binding host molecules.

\section{Fenestrindane-based nanographenes}

The fenestrindane skeleton consists of four indane units sharing one carbon atom, which is the center of two mutually fused spirane units. All-cis-fenestrindane is by far the most stable configuration and was first prepared by Kuck et al. (Figure 6). ${ }^{[45-46]}$ In contrast to the rigid, $C_{3 v}$-symmetric TBTQ framework, the skeleton of fenestrindane adopts $S_{4}$-symmetric molecular geometry in the solid state and is conformationally dynamic in solution. ${ }^{[47-48]}$ Hence, the four aromatic rings are not aligned in a coplanar fashion, rather they assume the shape of a slightly distorted saddle in the three-dimensional space. As a result, $\pi$-extension around the bay areas of fenestrindane should lead to nanographenes with a saddle-shaped geometry.

One of the earliest attempts was to use HBC moieties as the bay bridge elements of the fenestrindane core (Scheme $6){ }^{[49]}$ Similar to the very first approach leading to the merged TBTQ-HBC hydrocarbon $\mathbf{2}$, bay bridging was conducted via the peripheral positions (C-2 and $\mathrm{C}-11)$ of 


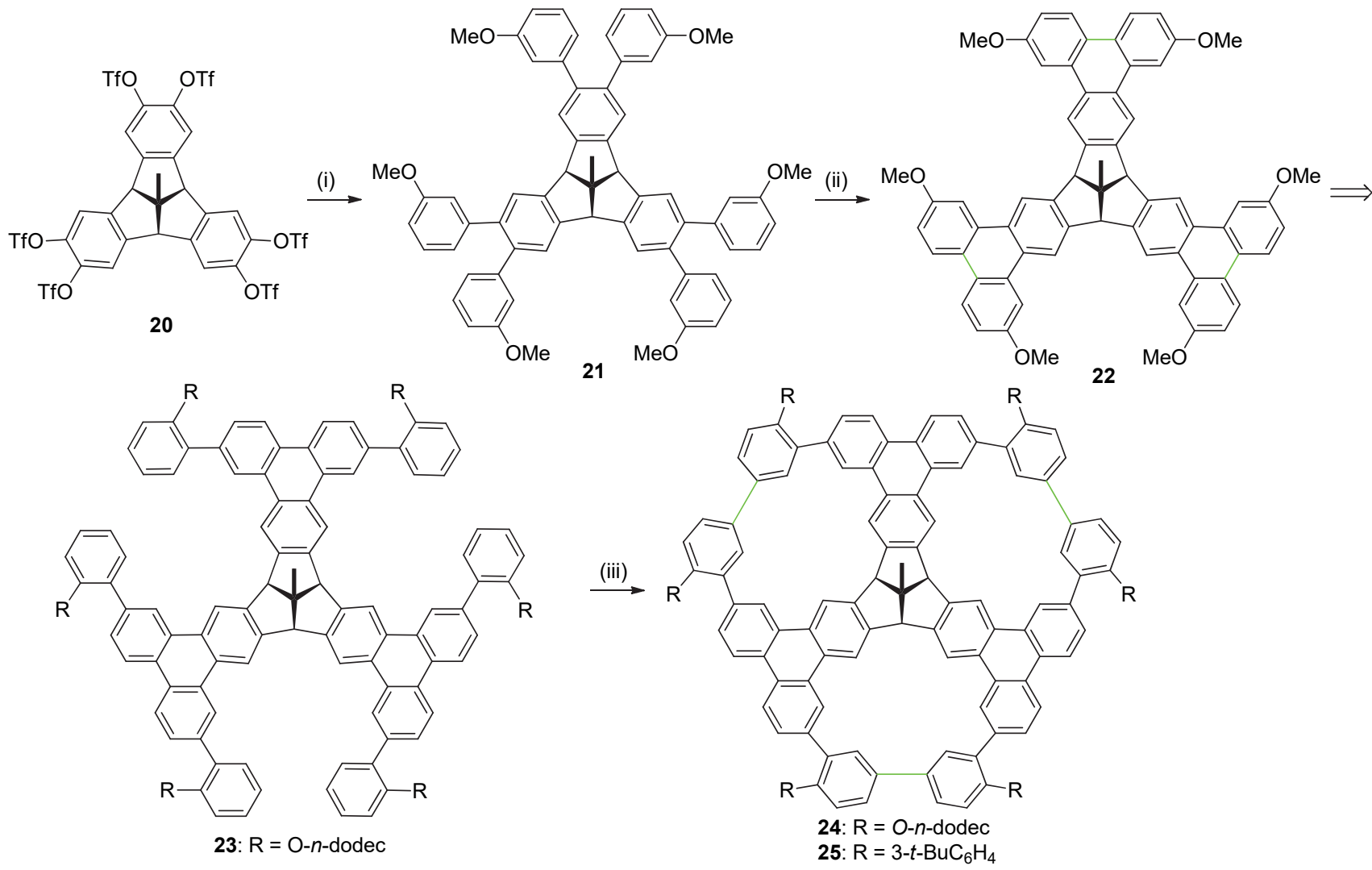

Reagents and conditions: (i) $\mathrm{Pd}_{2}(\mathrm{dba})_{3}$, SPhos, $\mathrm{Cs}_{2} \mathrm{CO}_{3}, \mathrm{H}_{2} \mathrm{O}$ /toluene, $120{ }^{\circ} \mathrm{C}, 95 \%$; (ii) $\mathrm{FeCl}_{3}, \mathrm{CH}_{2} \mathrm{Cl}_{2}, 22{ }^{\circ} \mathrm{C}$; (iii) for compound 24: $\mathrm{DDQ}$, $\mathrm{TfOH}, \mathrm{CH}_{2} \mathrm{Cl}_{2}, 0{ }^{\circ} \mathrm{C}$

Scheme 5 Synthesis of the nonplanar porous nanographene 24 via threefold Scholl-type macrocyclization (newly formed bonds highlighted in green)

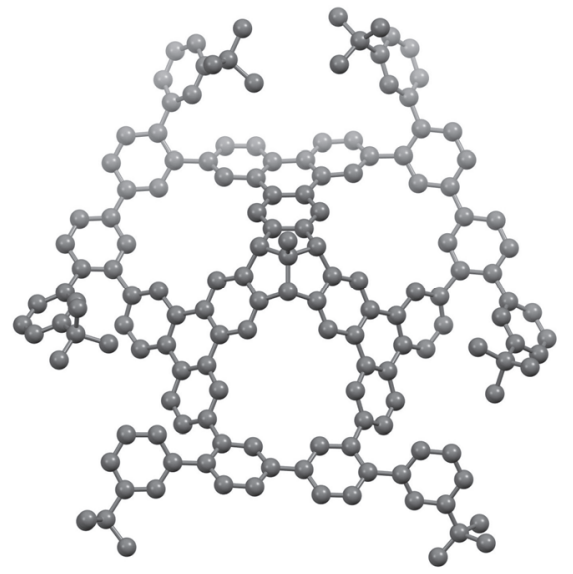

Figure 5 Crystal structure of compound $\mathbf{2 5}$
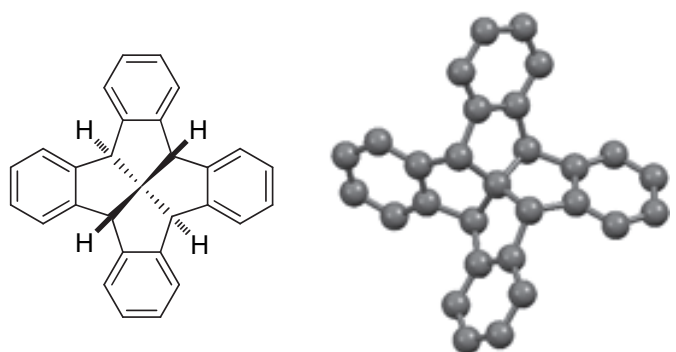

Figure 6 Structure and three-dimensional geometry of all-cisfenestrindane the fenestrindane unit. The bis(pentaarylphenyl)-appended fenestrindanes $\mathbf{2 7}$ and $\mathbf{2 8}$ could be prepared from bis(triflate) 26. Our initial attempt employed the unsubstituted derivative 27. However, an insoluble solid was obtained under various Scholl reaction conditions and the structural identity of the product could not be confirmed. A soluble derivative $\mathbf{2 8}$ bearing $t$-butyl substituents was then prepared, which underwent twelve hexagonal ring formation steps to produce compound $\mathbf{2 9}$ in excellent yield. However, the crucial twofold cycloheptatriene ring formation could not be realized-ironically because of the steric hindrance induced by the $t$-butyl residues (highlighted in red) adjacent to the bay areas.

Faced with this problem, we then reverted to a similar strategy used in the TBTQ bay bridging via bay area substitution. Again, direct electrophilic aromatic functionalization of fenestrindane leads exclusively to peripheral substitution. ${ }^{[12-13]}$ Fortunately, the bay areas of fenestrindane are less sterically hindered than those of TBTQ because of its $S_{4}$ symmetry and conformational flexibility. The adjacent aromatic units are located further away from each other. Hence, installation of four substituents at the C-1, C-4, C-9 and C-12 bay positions could proceed in good yield prior to forming the fenestrindane skeleton. To this end, the tetrakis(triflate) 32 could be prepared in large quantities using the literature procedure ${ }^{[46]}$ from starting materials 30 and 31 (Scheme 7). ${ }^{[50]}$ This compound was 


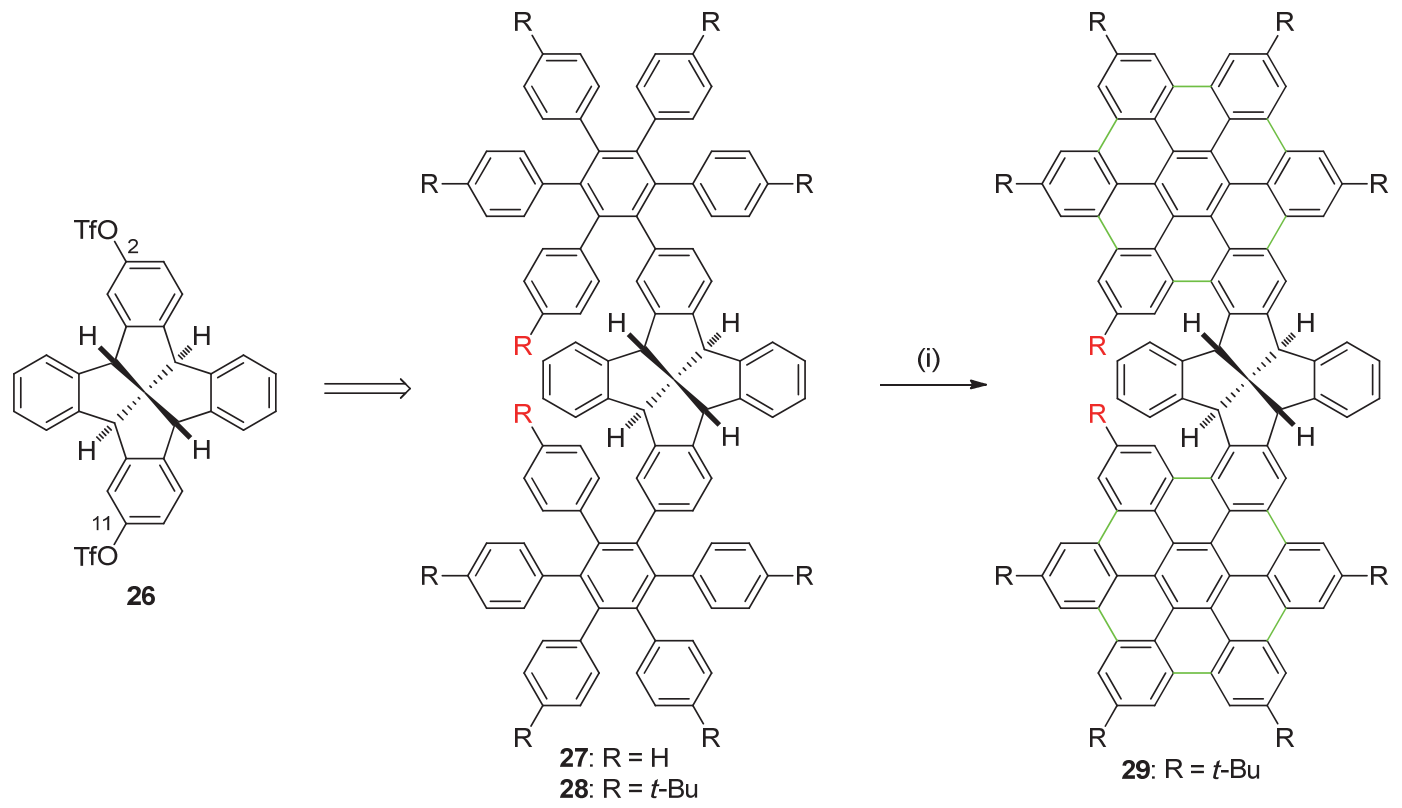

Reagents and conditions: (i) $\mathrm{FeCl}_{3}, \mathrm{CH}_{3} \mathrm{NO}_{2}, 20{ }^{\circ} \mathrm{C}, 90 \%$

Scheme 6 Unsuccessful attempts to bay bridging of a fenestrindane core with two HBC units (newly formed bonds highlighted in green)
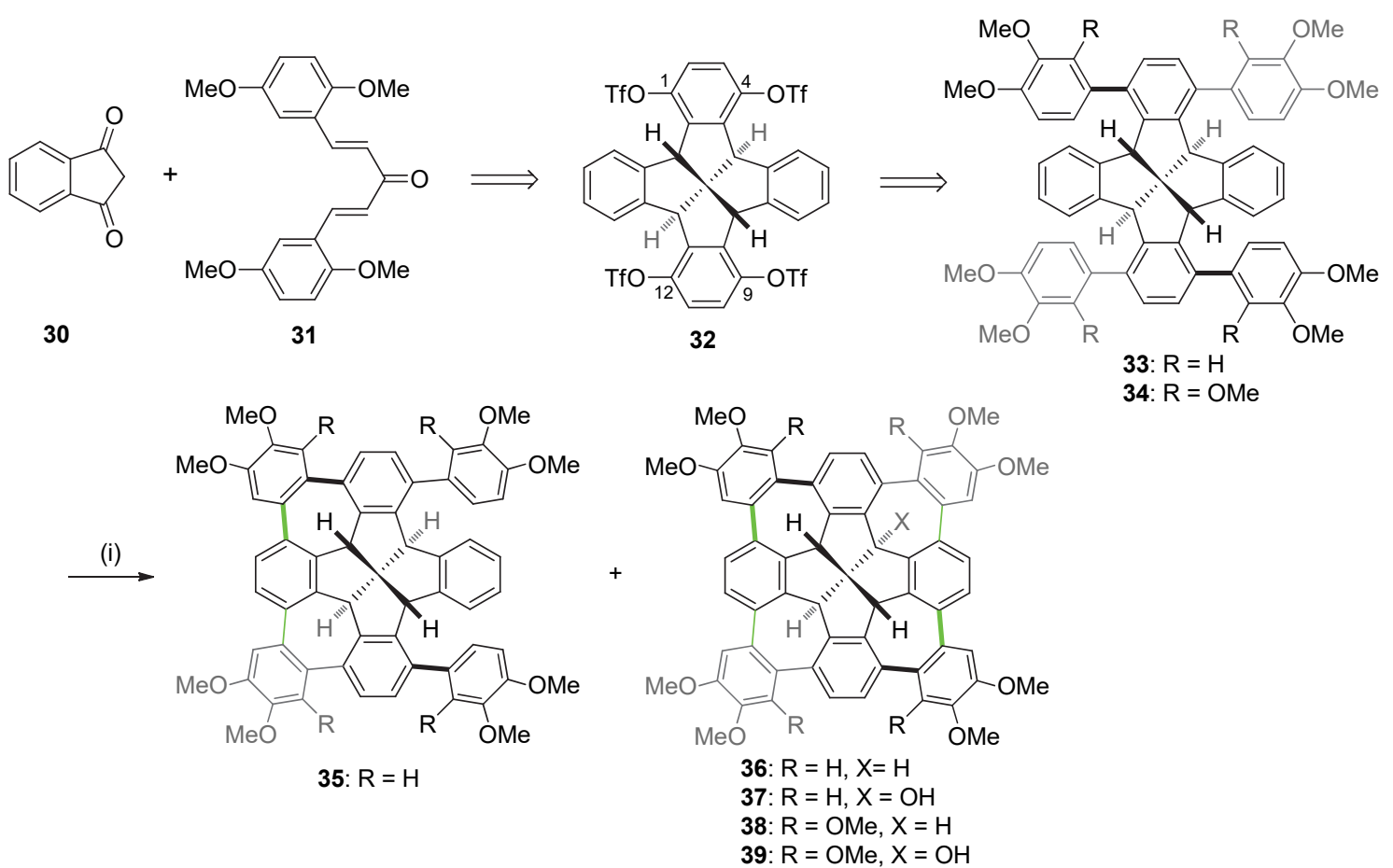

34: $\mathrm{R}=\mathrm{OMe}$

Reagents and conditions: (i) $\mathrm{DDQ}, \mathrm{TfOH}, \mathrm{CH}_{2} \mathrm{Cl}_{2}, 0{ }^{\circ} \mathrm{C}$

Scheme 7 Twofold and fourfold bay bridging of the fenestrindane core with electron-rich aryl units (newly formed bonds highlighted in green)

then converted into two electron-rich 1,4,9,12-tetraarylsubstituted fenestrindanes $\mathbf{3 3}$ and $\mathbf{3 4}$ via Suzuki-Miyaura coupling. Upon treatment of $\mathbf{3 3}$ with DDQ and triflic acid, twofold-cyclization 35 (10\%), fourfold-cyclization products $36(45 \%)$ and 37 (4\%) were formed. Compound 37 was an over-oxidation product formed by hydroxylation at one of the bridgehead positions. Similarly, compound 34 afforded the fourfold-cyclization products 38 (52\%) and 39 $(20 \%)$. It should be noted that no products of single and triple cyclization were formed in these reactions. Furthermore, only the C-shaped doubly cyclized product $\mathbf{3 5}$ was generated, the other possible S-shaped and U-shaped doubly cyclized products were not found.

X-Ray crystallographic analysis of compound 36 re- 
vealed its saddle-shaped geometry. ${ }^{[51]}$ As compared to parent $o, p, o, p, o, p, o, p$-cyclooctaphenylene, which lacks the all-cis-[5.5.5.5]fenestrindane core, it possesses a shallower saddle structure. Incidentally, the veratrole units within each pair of opposite benzocycloheptatriene moieties of $\mathbf{3 6}$ possess nearly orthogonal orientation to each other, suggesting that it could be utilized to construct deeply concave receptors or larger-size molecular squares (Figure 7).

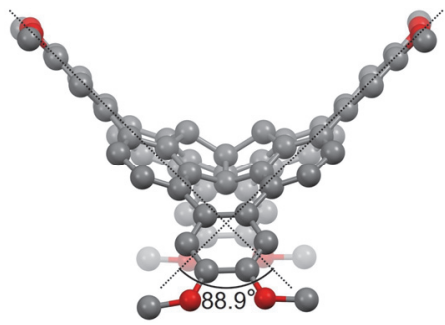

Figure 7 X-Ray crystal structure of compound $\mathbf{3 6}$

In contrast to the case of TBTQ, it was later found that electron-rich aryl rings are not required for the successful fourfold cycloheptatriene formation. Hence, 1,4,9,12tetraphenylfenestrindane $\mathbf{4 0}$ could undergo fourfold cyclization with concomitant double hydroxylation to give product $44(8 \%)$. Similarly, 1,4,9,12-tetrakis-(3,4-dimethylphenyl)fenestrindane $\mathbf{4 1}$ afforded the fourfoldcyclization product $43(18 \%)$ together with the corresponding derivative 45 (4\%) formed by single hydroxylation. ${ }^{[52]}$ Fortunately, the hydroxylated side products could be easily converted to 42 and 43 using $\mathrm{Et}_{3} \mathrm{SiH} / \mathrm{CF}_{3} \mathrm{CO}_{2} \mathrm{H}$ (Scheme 8). In the same work, one unsymmetrically substituted fenestrindane-based saddle $\mathbf{5 1}$ was also successfully prepared from compound $\mathbf{5 0}$ (Scheme 9). More recently, a similar fourfold cycloheptatriene formation around a resorcin[4] arene core was reported by Lucas. ${ }^{[33]}$

Similar to the case of TBTQ, bay-bridged fenestrindane saddles such as $\mathbf{3 6}$ are promising starting points for further $\pi$-extension to larger nanographenes such as $\mathbf{5 2}$ (Scheme 10). Compound 51, on the other hand, could be used to prepare deeply concave U-shaped molecules such as $\mathbf{5 3}$ via chirality-assisted dimerization, ${ }^{[54]}$ as several fenestrindane precursors have already been optically resolved. ${ }^{[55]}$

\section{Conclusions}

We demonstrated that two different molecular geometries, namely, wizard hat-shaped and saddle-shaped polyaromatic structures, can be obtained from suitably functionalized TBTQ and fenestrindane derivatives, respectively, using a bottom-up synthesis strategy. The key to the successful synthesis of these molecules rests on the installation of electron-rich aryl moieties in the bay areas of the structurally-rigid TBTQ or fenestrindane skeleton. Further $\pi$-expansion of these non-planar molecules via the peripheral functionalized alkoxy groups should furnish much larger nanographenes or nanaomeshs for further investigations. These carbon-rich products are potentially useful

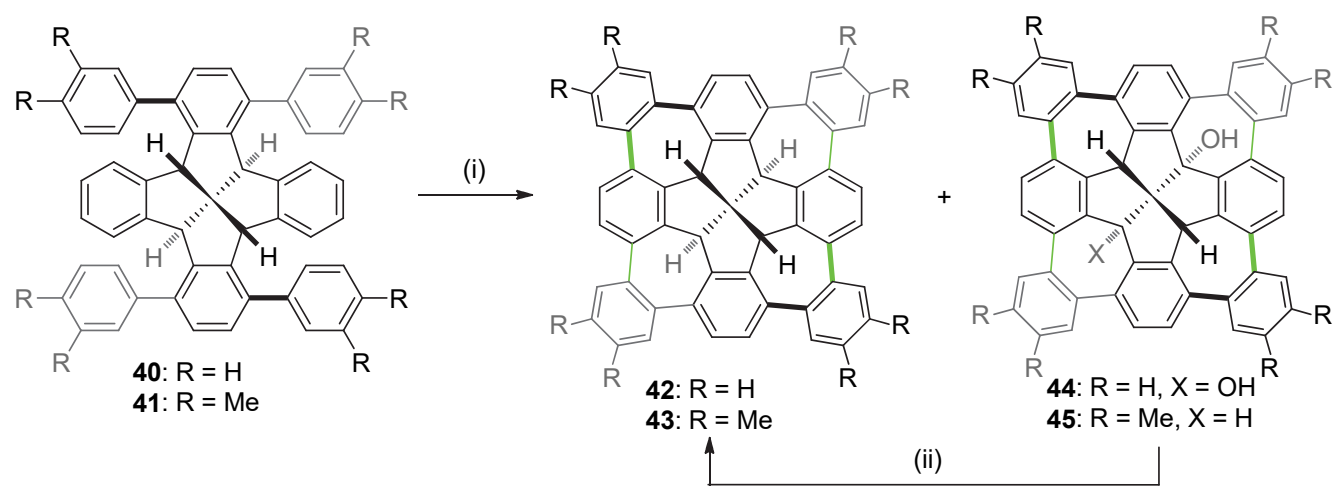

Reagents and conditions: (i) $\mathrm{DDQ}, \mathrm{TfOH}, \mathrm{CH}_{2} \mathrm{Cl}_{2}, 0{ }^{\circ} \mathrm{C}$; (ii) $\mathrm{Et}_{3} \mathrm{SiH} / \mathrm{CF}_{3} \mathrm{CO}_{2} \mathrm{H}, \mathrm{CH}_{2} \mathrm{Cl}_{2}, 22{ }^{\circ} \mathrm{C}$

Scheme 8 Successful fourfold bay bridging of 1,4,9,12- tetraarylfenestrindanes without electronic activation by methoxy substituents (newly formed bonds highlighted in green)
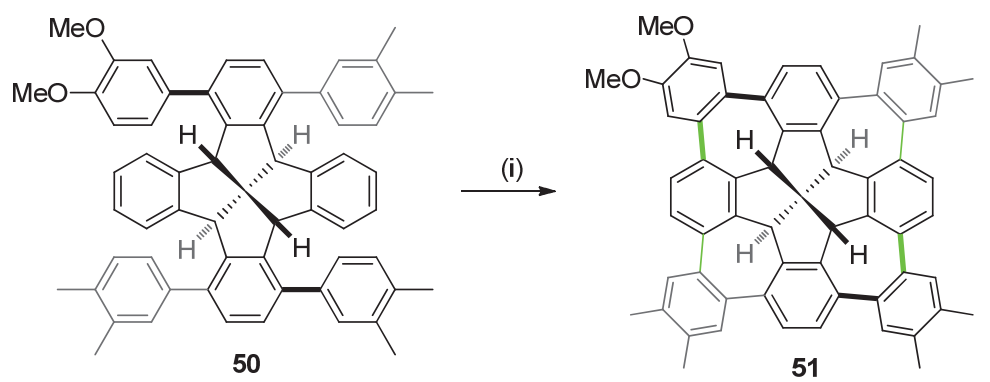

Reagents and conditions: (i) DDQ, TfOH, $\mathrm{CH}_{2} \mathrm{Cl}_{2}, 0{ }^{\circ} \mathrm{C}$; then $\mathrm{Et}_{3} \mathrm{SiH} / \mathrm{CF}_{3} \mathrm{CO}_{2} \mathrm{H}, \mathrm{CH}_{2} \mathrm{Cl}_{2}, 22{ }^{\circ} \mathrm{C}$

Scheme 9 Synthesis of an unsymmetrically substituted fenestrindane saddle (newly formed bonds highlighted in green) 


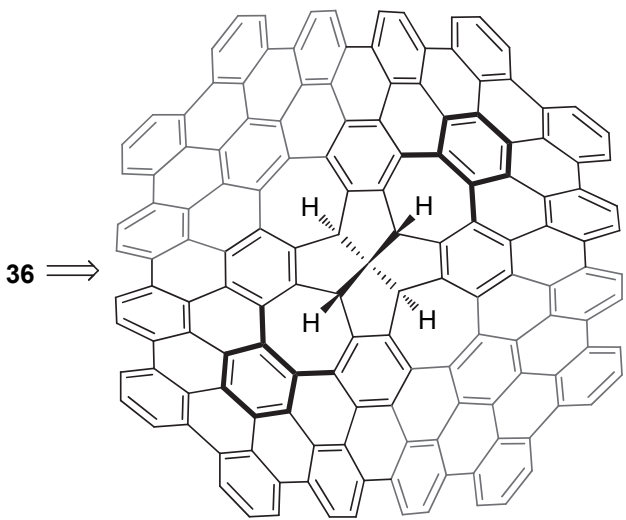

52

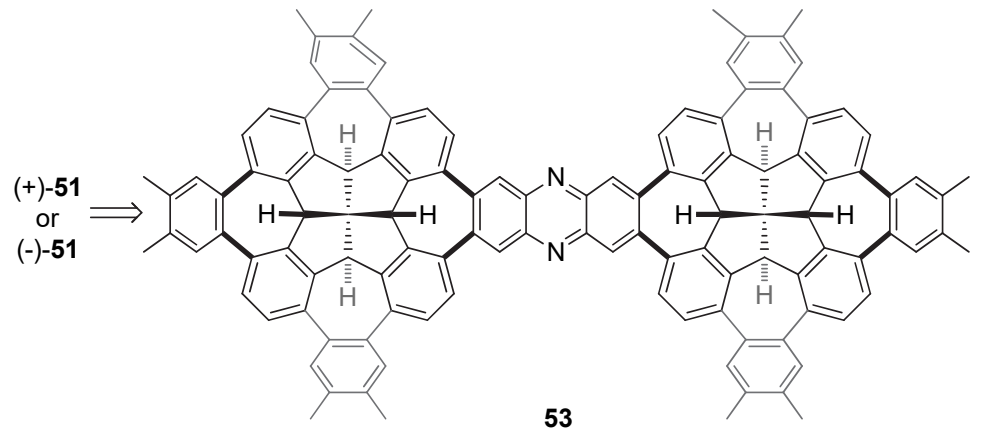

53

Scheme 10 Potential interesting targets from fenestrindane-based saddles

materials for host-guest complexation, supramolecular, optoelectronic, sensing and catalysis applications. Works are underway in our laboratories to pursue these goals.

\section{References}

[1] Narita, A.; Wang, X.-Y.; Feng, X.; Müllen, K. Chem. Soc. Rev. 2015, 44, 6616.

[2] Segawa, Y.; Ito, H.; Itami, K. Nat. Rev. Mater. 2016, 1, 15002.

[3] Márquez, I. R.; Castro-Fernández, S.; Millána, A.; Campaña, A. G. Chem. Commun. 2018, 54, 6705.

[4] Higashibayashi, S.; Sakurai, H. In Polycyclic Arenes and Heteroarenes: Synthesis, Properties, and Applications, Ed.: Miao, Q., Wiley-VCH, Weinheim, 2016, p. 61.

[5] Cheung, K. Y.; Miao, Q. In Polycyclic Arenes and Heteroarenes: Synthesis, Properties, and Applications, Ed.: Miao, Q., Wiley-VCH, Weinheim, 2016, p. 85.

[6] Deng, C.-L.; Peng, X.-S.; Wong, H. N. C. In Polycyclic Arenes and Heteroarenes: Synthesis, Properties, and Applications, Ed.: Miao, Q., Wiley-VCH, Weinheim, 2016, p. 111.

[7] Yamago, S.; Kayahara, E.; Hashimoto, S. In Polycyclic Arenes and Heteroarenes: Synthesis, Properties, and Applications, Ed.: Miao, Q., Wiley-VCH, Weinheim, 2016, p. 143.

[8] Collins, S. K.; Grandbois, A.; Vachon, M. P.; Côté, J. Angew. Chem., Int. Ed. 2006, 45, 2923.

[9] Fujikawa, T.; Segawa, Y.; Itami, K. J. Am. Chem. Soc. 2015, 137, 7763.

[10] Kashihara, H.; Asada, T.; Kamikawa, K. Chem.-Eur. J. 2015, 21 , 6523 .

[11] Tellenbröker, J.; Kuck. D. Angew. Chem., Int. Ed. 1999, 38, 919.

[12] Tellenbröker, J.; Kuck. D. Eur. J. Org. Chem. 2001, 1483.

[13] Kuck, D. Chem. Rev. 2006, 106, 4885.

[14] Kuck, D. Angew. Chem., Int. Ed. Engl. 1984, 23, 508.

[15] Kuck, D.; Lindenthal, T.; Schuster, A. Chem. Ber. 1992, 125, 1449.

[16] Kuck, D.; Schuster, A.; Krause, R. A.; Tellenbröker, J.; Exner, C. P.; Penk, M.; Bögge, H.; Müller, A. Tetrahedron 2001, 57, 3587.

[17] Kuck, D. Pure Appl. Chem. 2006, 78, 749.

[18] Brandenburg, J. G.; Grimme, S.; Jones, P. G.; Markopoulos, G.; Hopf, H.; Cyranski, M. K.; Kuck, D. Chem.-Eur. J. 2013, 19, 9930.

[19] Xu, W.-R.; Xia, G.-J.; Chow, H.-F.; Cao, X.-P.; Kuck, D. Chem.Eur. J. 2015, 21, 12011.

[20] Strübe, J.; Neumann, B.; Stammler, H.-G.; Kuck, D. Chem.-Eur. J. 2009, 15, 2256.

[21] Klotzbach, S.; Scherpf, T.; Beuerle, F. Chem. Commun. 2014, 50, 12454.
[22] Klotzbach, S.; Beuerle, F. Angew. Chem., Int. Ed. 2015, 54, 10356.

[23] Beaudoin, D.; Rominger, F.; Mastalerz, M. Angew. Chem., Int. Ed. 2016, 55, 15599.

[24] Kirchwehm, Y.; Damme, A.; Kupfer, T.; Braunschweig, H.; Krueger, A. Chem. Commun. 2012, 48, 1502.

[25] Linke, J.; Bader, N.; Tellenbröker, J.; Kuck, D. Synthesis 2018, 50, 175.

[26] Kuck, D.; Linke, J.; Teichmann, L. C.; Barth, D.; Tellenbröker, J.; Gestmann, D.; Neumann, B.; Stammler, H.-G.; Bögge, H. Phys. Chem. Chem. Phys. 2016, 18, 11722.

[27] Mughal, E. U.; Kuck, D. Chem. Commun. 2012, 48, 8880.

[28] Scholl, R.; Mansfeld, J. Ber. Dtsch. Chem. Ges. 1910, 43, 1734.

[29] Grzybowski, M.; Skonieczny, K.; Butenschön, H.; Gryko, D. T. Angew. Chem., Int. Ed. 2013, 52, 9900 .

[30] Grzybowski, M.; Sadowski, B.; Butenschön, H.; Gryko, D. T. Angew. Chem., Int. Ed. 2020, 59, 2998.

[31] Mughal, E. U.; Neumann, B.; Stammler, H.-G.; Kuck, D. Eur. J. Org. Chem. 2014, 2014, 7469.

[32] Rempala, P.; Kroulík, J.; King, B. T. J. Org. Chem. 2006, 71, 5067.

[33] King, B. T.; Kroulík, J.; Robertson, C. R.; Rempala, P.; Hilton, C. L.; Korinek, J. D.; Gortari, L. M. J. Org. Chem. 2007, 72, 2279.

[34] Ip, H.-W.; Ng, C.-F.; Chow, H.-F.; Kuck, D. J. Am. Chem. Soc. 2016, $138,13778$.

[35] Ip, H.-W.; Chow, H.-F.; Kuck, D. Org. Chem. Front. 2017, 4, 817.

[36] CCDC-1474467 contains the crystallographic data for 10.

[37] Fujioka, Y. Bull. Chem. Soc. Jpn. 1984, 57, 3494.

[38] Bieri, M.; Treier, M.; Cai, J.; Ait-Mansour, K.; Ruffieux, P.; Gröning, O.; Gröning, P.; Kastler, M.; Rieger, R.; Feng, X.; Müllen, K.; Fasel, R. Chem. Commun. 2009, 6919.

[39] Liu, Y.; Narita, A.; Teyssandier, J.; Wagner, M.; De Feyter, S.; Feng, X.; Müllen, K. J. Am. Chem. Soc. 2016, 138, 15539.

[40] Idelson, A.; Sterzenbach, C.; Jester, S.-S.; Tschierske, C.; Baumeister, U.; Höger. S. J. Am. Chem. Soc. 2017, 139, 4429.

[41] Ikemoto, K.; Kobayashi, R.; Sato, S.; Isobe, H. Angew. Chem., Int. Ed. 2017, 56, 6511.

[42] He, L.; Ng, C.-F.; Li, Y.; Liu, Z.; Kuck, D.; Chow, H.-F. Angew. Chem., Int. Ed. 2018, 57, 13635.

[43] CCDC-1850232 contains the crystallographic data for $\mathbf{2 5}$.

[44] Majewski, M. A.; Hong, Y.; Lis, T.; Gregoliński, J.; Chmielewski, P. J.; Cybińska, J.; Kim, D.; Stępień, M. Angew. Chem., Int. Ed. 2016, $55,14072$.

[45] Kuck, D.; Bögge, H. J. Am. Chem. Soc. 1986, 108, 8107.

[46] Kuck, D. Chem. Ber. 1994, 127, 409.

[47] Kuck, D. In Advances in Theoretically Interesting Molecules, Vol. 4, Ed.: Thummel, R. P., JAI Press, Greenwich, London, 1998, p. 81. 
[48] Kuck, D.; Schuster, A.; Krause, R. A. J. Org. Chem. 1991, 56, 3472 .

[49] An, P.; Chow, H.-F.; Kuck, D. Synlett 2016, 27, 1255.

[50] Wong, W.-S.; Ng, C.-F.; Kuck, D.; Chow, H.-F. Angew. Chem., Int. Ed. 2017, 56, 12356.

[51] CCDC-1528883 contains the crystallographic data for $\mathbf{3 6}$.

[52] Wong, W.-S.; Lau, W.-W.; Li, Y.; Liu, Z.; Kuck, D.; Chow, H.-F.
Chem.-Eur. J. 2020, 26, 4310.

[53] Smith, J. N.; Lucas, N. T. Chem. Commun. 2018, 54, 4716.

[54] Liu, X.; Weinert, Z. J.; Sharafi, M.; Liao, C.; Li, J.; Schneebeli, S. T. Angew. Chem., Int. Ed. 2015, 54, 12772.

[55] Wong, W.-S.; Tse, H.-W.; Cheung, E.; Kuck, D.; Chow, H.-F. J. Org. Chem. 2019, 84, 869 . 